\title{
Lipid peroxidation and hepatic antioxidants in alcoholic liver disease
}

\author{
R D Situnayake, B J Crump, D I Thurnham, J A Davies, J Gearty, M Davis
}

\begin{abstract}
The generation of hepatic liver peroxidation by free radicals has been proposed as a mechanism for ethanol induced hepatotoxicity. To investigate this hypothesis, lipid extracts from hepatic needle biopsy specimens from alcoholic subjects were examined for evidence of lipid peroxidation by measuring total conjugated dienes by derivative spectroscopy and, after hydrolysis of hepatic lipid extract and reverse phase high performance liquid chromatography, the molar ratio between a diene-conjugated linoleic acid isomer (18:2 $(9,11)$ and the parent linoleic acid isomer $(18: 2(9,12))$. Changes were related to hepatic histology, iron deposition, glutathione and vitamin E values. Derivative spectroscopy minima suggestive of diene conjugation were identified at 233 and $242 \mathrm{~nm}$ and correlated weakly, suggesting these two minima may represent different classes of lipid dienes. There was a weak relation with inflammatory histological changes in the biopsy specimen but no correlation with hepatic iron grade, glutathione, or vitamin $E$ lipid ratio. The proportion of 18:2(9,11) linoleic acid in hepatic lipids correlated significantly with inflammatory histological features and inversely with hepatic glutathione. Furthermore, hepatic glutathione was lower in biopsy specimens with greater iron staining. The ratio of vitamin E to lipid was not related to histological group, inflammation, or iron grade. These findings suggest that excess alcohol consumption leads to hepatic inflammation and lipid peroxidation.
\end{abstract}

The mechanism by which ethanol consumption leads to hepatotoxicity is unknown. The generation of hepatic lipid peroxidation by highly reactive free radicals was first proposed as a mechanism by di Luzio and Hartman' and later by other workers, ${ }^{2-6}$ and led to further studies which indicated that hepatic concentrations of the antioxidant tripeptide glutathione may be reduced by ethanol, either by increased utilisation $^{7}$ or diminished production. ${ }^{8} \mathrm{~A}$ role for the antioxidant vitamin $\mathrm{E}$ in this process was also suggested. ${ }^{9}$

In studies in the rat, extremely high doses of ethanol are required to produce hepatotoxicity with the characteristics of free radical induced lipid peroxidation, when given acutely,,$^{10}$ though the changes may be potentiated by chronic dosing. "In the baboon, however, smaller acute doses may lead to similar changes which may be prevented by pretreatment with methionine, a precursor for the antioxidant glutathione." Human evidence for this type of process is limited and centres on the detection of markers of free radical attack on polyunsaturated fatty acids. Shaw $e t$ al $^{7}$ found increased values of one such marker (diene conjugation) in hepatic tissue taken from 16 alcoholics with different stages of liver injury, when compared with a control group with liver damage unrelated to alcohol. Similarly, an increase of malonaldehyde in liver biopsy specimens also suggested hepatic lipid peroxidation in alcoholics. ${ }^{12}$

Free radical attack on polyunsaturated fatty acids characteristically causes a rearrangement of the double bonds to generate diene conjugated lipids. This change is detected by the development of absorbance at $233-245 \mathrm{~nm}$ in lipid extracts. ${ }^{13}$ The nature of diene conjugation in human plasma and some other tissues has been attributed to the presence of non-peroxide conjugated diene stereoisomer of linoleic acid, 18:2 (9cis, 11 trans) linoleic acid $(9,11 \mathrm{LA})$, which may be generated in vitro by ultraviolet irradiation of 18:2 $(9,12)$ linoleic acid $(9,12 \mathrm{LA})$ in the presence of protein. ${ }^{13}$ The proportion of plasma phospholipid esterfied diene-conjugated 9,11 LA is increased acutely in alcoholics who are still drinking and falls after ethanol withdrawal, supporting the suggestion that ethanol induces free radical generation in the liver. ${ }^{14}$

Diene conjugation can also be detected and quantified using derivative spectroscopy. ${ }^{15}$ Using this technique, derivative spectroscopy minima at $242 \mathrm{~nm}$ and $233 \mathrm{~nm}$ (equivalent to absorption maxima in normal absorption spectroscopy) have been found in hepatic lipid extracts from animals poisoned with the hepatotoxin carbon tetrachloride and were attributed to a mixture of cis,trans and trans, trans lipid diene hydroperoxides. ${ }^{16}$ From the order of appearance of these minima, it was suggested that the relative proportion of the different stereoisomers reflects the cellular redox status within the liver. ${ }^{16}$

To examine the inter-relation between lipid peroxidation and antioxidants in ethanol induced hepatic injury, we have measured diene conjugation and the hepatic antioxidants glutathione and vitamin $\mathrm{E}$ in hepatic needle biopsy specimens from heavy drinkers. Since reactive oxygen species are also generated in the inflammatory process ${ }^{17}$ and iron may play a catalytic role in free radical reactions, ${ }^{18-20}$ these measures have been correlated with histological appearance, degree of hepatitis, and iron loading.

\section{Subjects and methods}

Forty three patients were studied. All underwent liver biopsy as part of a programme of assessment and treatment for alcohol abuse and gave informed consent. The study was approved by 
the local ethical committee. Each patient had been drinking at least $100 \mathrm{~g}$ ethanol a day for a minimum of one year. All were inpatients and had abstained from-alcohol for 72 hours before the biopsy. Only tissue in excess of that required for routine histological purposes was available for study. The portion of liver available thus varied between subjects and not all analyses could be performed on all samples. The available tissue was immediately placed in a container of liquid nitrogen by the bedside and remained under liquid nitrogen until immediately before analysis. Laboratory reagents were purchased from Sigma unless otherwise stated.

\section{HEPATIC LIPID EXTRACTION}

Where necessary biopsy specimens were divided into two samples (each of approximately $5 \mathrm{mg}$ ) immediately after thawing. One sample was refrozen at $-20^{\circ} \mathrm{C}$ for further analysis for glutathione and protein (see below). Lipids were extracted by the method of Burton et al..$^{21}$ Tissue was homogenised in $100 \mu \mathrm{l}$ ice cold $0.1 \mathrm{mmol} / \mathrm{l}$ sodium dodecyl sulphate, vortexed for one minute with $200 \mu \mathrm{l}$ absolute ethanol (Spectrosol, $\mathrm{BDH}, \mathrm{UK}$ ) and then with $800 \mu \mathrm{l}$ heptane (high performance liquid chromatography (HPLC) grade, Rathburn Chemicals) for a further minute. The mixture was centrifuged for 10 minutes at $2000 \mathrm{rpm}$ in a bench top centrifuge and the upper heptane layer was removed.

\section{TOTAL DIENE CONJUGATION AND TOTAL LIPID ASSAYS}

Total conjugated dienes were measured by second derivative spectroscopy of the heptane lipid extract. A Shimadzu double beam scanning spectrophotometer with capability for derivative spectroscopy was used. Operating conditions were as follows: an absorbance range was selected between $\pm 0.02-0.2$ absorbance units (aufs), scanning was started at $250 \mathrm{~nm}$ and ended at $220 \mathrm{~nm}$, recorded on a scale of $5 \mathrm{~nm} / \mathrm{cm}$, using a 'fast' scan speed and a $2 \mathrm{~nm}$ slit width. Sample and reference cells were first scanned over the operating spectrum and a background correction was 'memorised' to correct for any minor differences between cuvettes. Heptane extracts were scanned for absorbance and the second derivative spectra were obtained. Minima at $233 \mathrm{~nm}$ and $242 \mathrm{~nm}$ were identified and quantified in $\mathrm{mm}$ by measurement for minima to adjacent maxima at the higher wavelength ${ }^{15}$ on a printout. All values were adjusted to a detector sensitivity of \pm 0.02 aufs. The ratio of peak heights at minima $233 \mathrm{~nm}$ and $242 \mathrm{~nm}$ was calculated.

ASSAY OF TOTAL LIPIDS

Conjugated dienes were corrected for the lipid concentration in the heptane extract $(\mu \mathrm{mol} / \mathrm{l})$ assuming a molecular weight of 750 for hepatic lipids. Total lipids were measured as follows using the method of Snyder and Stevens. ${ }^{22}$ Stock reagent was prepared by dissolving $5 \mathrm{~g}$ ferric perchlorate in $10 \mathrm{ml} 71 \%(\mathrm{w} / \mathrm{v})$ perchloric acid and $10 \mathrm{ml}$ deionized water, and $100 \mathrm{ml}$ ice cold absolute ethanol were then added. Each day of assay, $4 \mathrm{ml}$ of the stock reagent was added to $3 \mathrm{ml}$ perchloric acid and $100 \mathrm{ml}$ ice cold ethanol (working reagent 1 ).

Alkaline hydroxyalamine was prepared daily by taking two aliquots each of $2.5 \mathrm{ml}$ deionized water; to one was added $2 \mathrm{~g}$ hydroxylamine-HCL (BDH Chemicals, UK) and into the second $4 \mathrm{~g}$ sodium hydroxide. Each preparation was subsequently dissolved in $50 \mathrm{ml}$ ice cold ethanol. The two resultant solutions were combined and centrifuged at $2000 \mathrm{rpm}$ for 10 minutes. The supernatant (working reagent 2 ) was used in the assay.

A total of $200 \mu$ l of heptane lipid extract was dried under nitrogen and resuspended in $300 \mu \mathrm{l}$ of working reagent 1 . The samples were incubated in stoppered tubes in a water bath at $65^{\circ} \mathrm{C}$ for two minutes and cooled in ice cold water, $750 \mu \mathrm{l}$ working solution 1 was added, vortex mixed, and allowed to stand for 20 minutes. Optical density was measured at 530 $\mathrm{nm}$ against an air blank. A daily standard curve was prepared using 1-100 $\mu \mathrm{l} 2 \mu \mathrm{mol} / \mathrm{l}$ glycerol trioleate in spectroscopic grade hexane $(1 \mu \mathrm{l}=$ $1.82 \mu \mathrm{g}$ lipid).

\section{HEPATIC VITAMIN E}

Hepatic vitamin E was measured using $20 \mu \mathrm{l}$ of the heptane lipid extract as described by Thurnham et $\mathrm{l}^{23}$ using normal phase HPLC on a $250 \times 4.6 \mathrm{~mm}$ column of $5 \mu \mathrm{m}$ particles of Lichrosorb Si60. The mobile phase was heptane: isopropanol (99:1). Peak detection was by a fluorescence detector (Perkin Elmer LS-1) with two interference filters; ex $280 \mathrm{~nm}$, em $330 \mathrm{~nm}$. Peak areas were quantified (CI-10 computing integrators, Laboratory Data Control) using response factors derived from freshly prepared external standards in heptane ( $\alpha$ tocopherol $23 \cdot 2$ $\mu \mathrm{m} / \mathrm{l}$; Sigma, UK). Standards were injected after every fourth sample and gave a coefficient of variation of $6.2 \%$ within batch. Values were expressed as the ratio of vitamin $\mathrm{E}$ to lipid $(\mu \mathrm{mol} / \mathrm{mmol})$.

\section{LINOLEIC ACID ISOMERS}

The remaining heptane lipid extract was blown to dryness under nitrogen, hydrolysed for 30 minutes at $65^{\circ} \mathrm{C}$ with $1 \mathrm{ml}$ methanolic potassium hydroxide $(2 \mathrm{~mol} / \mathrm{l})$ in stoppered glass tubes under nitrogen, and the $\mathrm{pH}$ was adjusted to $7 \cdot 4$ with $3 \mathrm{~mol} / 1$ hydrochloric acid. The extract was poured onto $3 \mathrm{cc} \mathrm{C} 18$ solid phase extraction columns (Bond Elut, Analytichem Int). Free fatty acids were eluted from the column using $1 \mathrm{ml}$ 2:1 propan-2-ol: acetonitrile (HPLC grade 'S', Rathburn Chemicals, Peebleshire, UK).

Samples of $20 \mu \mathrm{l}$ were injected onto a $250 \times 4.6 \mathrm{~mm}$ column of $5 \mu \mathrm{m}$ particles of Spherisorb ODS2 using a $50 \times 4.6 \mathrm{~mm}$ pellicular silica precolumn (Technicol Ltd). The mobile phase (acetonitrile:methanol:acetic acid, $90: 10: 0 \cdot 1)$ was pumped at $2 \mathrm{ml}$ per minute and ultraviolet absorbance was monitored by twin ultraviolet detectors set in series to measure conjugated dienes and native polyunsaturated fatty acids at $234 \mathrm{~nm}$ and $205 \mathrm{~nm}$ respectively. ${ }^{24}$ Response factors and peak identification were 
determined using external standards of 18:2 $(9,12)$ LA (Sigma, UK) and 18:2 $(9,11)$ LA (a gift from Dr T Dormandy, Department of Chemical Pathology, Whittington Hospital, London) prepared in propan-2-ol: acetonitrile (2:1) and allowed peak identification. Peak areas were quantified using CI-10 computing integrators (Laboratory Data Control). The percentage molar ratio, $\mathrm{R} ;[18: 2(9,11) \mathrm{LA}] \times 100 /[18: 2(9,12)$ LA] was calculated.

\section{TOTAL HEPATIC GLUTATHIONE}

Total glutathione was measured by an adaptation of the method of Beutler et al. ${ }^{25}$ Hepatic tissue $(5 \mathrm{mg}$ ) was homogenised in $200 \mu \mathrm{l} 0.5 \mathrm{~mol} / 1$ Tris$\mathrm{HCl}, \mathrm{pH} \mathrm{7 \cdot 4}$. A $20 \mu \mathrm{l}$ aliquot was removed for protein assay (see below). The remaining homogenate was vortex mixed in $200 \mu \mathrm{l} 0.5 \mathrm{~mol} / \mathrm{l}$ perchloric acid to precipitate protein. After centrifugation, $300 \mu \mathrm{l}$ of the supernatant was added to $600 \mu \mathrm{l} 0.3 \mathrm{~mol} / 1 \mathrm{Na}_{2} \mathrm{HPO}_{4}$ and $150 \mu \mathrm{l}$ Ellman's reagent prepared by combining $200 \mathrm{mg}$ 5,5' dithiobis-2-nitrobenzoic acid and $5 \mathrm{~g}$ sodium citrate in 1 litre HPLC grade water (Rathburn Chemicals). After incubation at $37^{\circ} \mathrm{C}$ for 10 minutes, the yellow colour formed was measured against a reagent blank at $412 \mathrm{~nm}$ in a Pye Unicam double beam spectrophotometer (SP1800). Standardisation was against a daily standard curve prepared with fresh glutathione $(1-10 \mu \mathrm{mol} / \mathrm{l})$. The coefficient of variation for this method was $3.5 \%$ within batch at the midpoint of the standard curve. Hepatic glutathione was corrected for protein, which was measured using $20 \mu$ l of the original homogenate and a commercially available kit (Biorad protein assay; Wako Chemicals) using human serum albumin (5-25 mg/l) as a standard (Sigma).

\section{HISTOLOGICAL EXAMINATION}

Standard paraffin sections were stained with haematoxylin and eosin, Orcein, and Perle's stain. All slides were examined by the same experienced hepatic pathologist (JG). In addition to the formal report, the degree of inflammation was recorded as 1,2 , or 3 ( 2 and 3 representing moderate and severe inflammation respectively) and the degree of iron staining in the biopsy specimen as 1 or 2 ( 2 representing increased iron staining). Grade 1 in each category corresponded to the normal appearance. Reanalysis with the observer blind to the previous score showed excellent agreement with the initial score.

TABLE I Hepatic conjugated dienes and antioxidants

\begin{tabular}{|c|c|c|c|c|c|}
\hline Variate & No & Median & IQ range & Minimum & Maximum \\
\hline $\begin{array}{l}\mathrm{D}_{233}(\mathrm{~mm} / \mu \mathrm{mol})^{\star} \\
\mathrm{D}_{242}(\mathrm{~mm} / \mu \mathrm{mol})^{\star} \\
\mathrm{D}_{242 / 233} \dagger \\
\text { Vitamin } \mathrm{E}(\mu \mathrm{mol} / \mathrm{mmol}) \\
\text { Glutathione }(\mu \mathrm{mol} / \mathrm{g} \text { protein }) \\
9,11 \mathrm{LA} \times 100 / 9,12 \mathrm{LA} ; \mathrm{R}^{\prime} \ddagger\end{array}$ & $\begin{array}{l}39 \\
39 \\
39 \\
39 \\
41 \\
21\end{array}$ & $\begin{array}{c}0.51 \\
0.65 \\
2.05 \\
0.46 \\
30.9 \\
2.7\end{array}$ & $\begin{array}{c}0 \cdot 26-0 \cdot 72 \\
0 \cdot 40-1 \cdot 22 \\
1 \cdot 0-2 \cdot 47 \\
0 \cdot 28-0 \cdot 91 \\
25-41 \cdot 9 \\
1 \cdot 97-4 \cdot 25\end{array}$ & $\begin{array}{l}0.13 \\
0.029 \\
0.016 \\
0.04 \\
7 \cdot 8 \\
1 \cdot 21\end{array}$ & $\begin{array}{l}4 \cdot 76 \\
2 \cdot 87 \\
3 \cdot 2 \\
2 \cdot 56 \\
78 \\
6 \cdot 1\end{array}$ \\
\hline
\end{tabular}

*Diene conjugation (DC) measured using derivative spectroscopy (see text for full details of method). Absorbance minima at $233 \mathrm{~nm}\left(D_{233}\right)$ and $242 \mathrm{~nm}\left(D_{242}\right)$ in second derivative spectroscopy represent absorbance maxima in the ultraviolet spectrum. Results are expressed after adjustment to a detector scale of \pm 0.02 aufs and corrected for lipid measurement by the method of Snyder and Stephens. ${ }^{22}$

The ratio of DC measurements at D minima 242 and $D$ minima $233 \mathrm{~nm}$.

\$,11 LA (9,11 linoleic acid) measured by HPLC after hydrolysis of lipid extract (for method see text). Results expressed as the percentage molar ratio $[9,11 \mathrm{LA}] \times 100 /[9,12 \mathrm{LA}] ; \mathbf{R}$.

\section{STATISTICS}

All data were analysed using non-parametric statistics with the SPP package for personal computers (Timberlake Clarke, UK). Medians with interquartile range are quoted throughout. Grouped data were compared using nonparametric one way analysis of variance (ANOVA). Post hoc pairwise testing (Scheffe) was used to test for differences between groups. Correlations between variates were assessed by Spearman's method or linear regression analysis after normalisation of data by logarithmic transformation. Multiple linear regression was also performed using log transformed data. Significance is quoted for $\mathbf{p}<0.05$.

\section{Results}

The liver biopsy specimens from 41 patients were graded as follows: fatty liver (23 patients), mild hepatitis (nine patients), severe hepatitis (six patients), and cirrhosis (three patients). Inflammation in the biopsy specimen was graded 1 (normal), 2, and 3. Numbers in each group were 25,11 , and five respectively. Tissue iron was graded 1 (normal) or 2 . Nine of the 41 biopsy specimens were judged to fall into the category with greater iron staining. Insufficient tissue was available for all measurements to be performed on all biopsy specimens and the numbers in each category are indicated where appropriate. There was a weak positive correlation between inflammation grade and the degree of iron staining $\left(R_{S}\right.$ $0.355, \mathrm{n}=41, \mathrm{p}<0.02$ ).

Table I summarises the results for hepatic conjugated diene and antioxidant measurements. The subsequent analysis investigated the relations between hepatic morphology, antioxidant concentration, and conjugated dienes.

\section{CONJUGATED DIENE MEASUREMENTS}

Typical second derivative spectra of the lipid extracts of 2 representative liver biopsy speci-

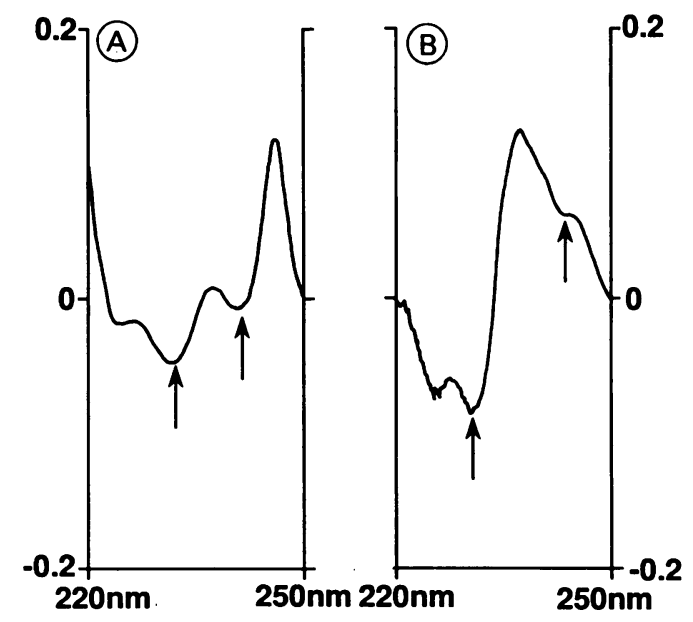

Figure 1: Typical second derivative spectra of heptane extracts from hepatic needle biopsy tissue.

The scans illustrate the minima (arrows) at $233 \mathrm{~nm}$ and 242 $\mathrm{nm}$ which correspond to absorption maxima in the ultraviolet spectrum. Measurements were made from minima to the adjacent maxima at the higher wavelength adjusted to a adjacent maxima at the higher wavelength adjusted to a
detector scale expansion of 0.02 aufs. Scan $(A)$ represents a predominance of absorption at $242 \mathrm{~nm}\left(D_{242}\right)$ while for scan (B) absorption at $233 \mathrm{~nm}$ predominates $\left(D_{233}\right)$. 


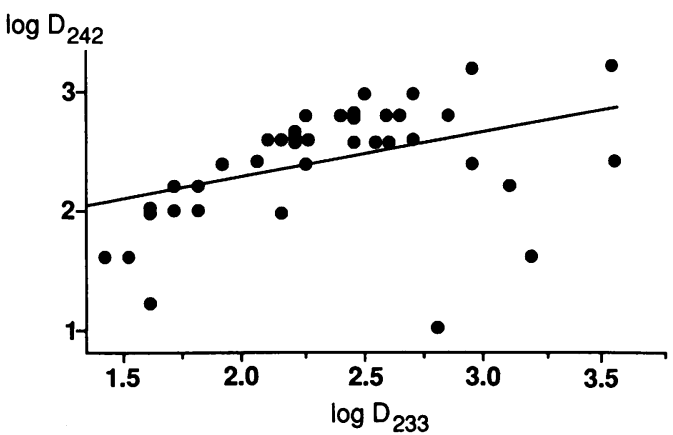

Figure 2: The relation between conjugated diene signals in the second derivative spectra of hepatic lipid extracts from heavy drinkers, after logarithmic transformation $\left(\log D_{242}\right.$ and $\log$ $\left.D_{233}\right)$ :

There was a significant correlation between the two variates $(r=0.433, n=39, p<0.006)$ expressed by the following equation; $\log D_{242}=0.433 \times \log D_{233}+1 \cdot 46$.

mens are shown in Figure $1(A)$ and (B). Minima in the second derivative spectra (which correspond to absorption maxima in the ultraviolet spectra) are seen at $233 \mathrm{~nm}\left(\mathrm{D}_{233}\right)$ and $242 \mathrm{~nm}$ $\left(D_{242}\right)$ and are similar to those found in rat liver extracts after carbon tetrachloride and ethanol poisoning. ${ }^{162}$ Figure $1(\mathrm{~A})$ and (B) illustrates the differences in relative proportions of the two diene peaks in different biopsy specimens. The two peaks have been interpreted to represent different classes of diene hydroperoxides and their relative proportions may be determined by the cellular redox status. ${ }^{16}$ There was a significant correlation between peak height of minima at $233 \mathrm{~nm}$ and $242 \mathrm{~nm}$ after logarithmic transformation $(R=0.433, n=39, p<0.006 ;$ Fig 2$)$. The peak height at $242 \mathrm{~nm}$ tended to be less when values of the corresponding peak at $233 \mathrm{~nm}$ were in the higher range, suggesting a curvilinear relation.

TABLE II Hepatic total dienes (minimum $233 \mathrm{~nm}$ ) in relation to hepatic morphology

\begin{tabular}{|c|c|c|c|c|c|c|c|}
\hline \multirow[b]{2}{*}{ Histological group } & \multirow[b]{2}{*}{ No } & \multicolumn{2}{|c|}{ Total dienes $(\min 233 \mathrm{~nm})$} & \multirow[b]{2}{*}{ Anova $H$} & \multirow[b]{2}{*}{$p<$} & \multirow[b]{2}{*}{ Scheffe } & \multirow[b]{2}{*}{$p<$} \\
\hline & & Median * & IQ range & & & & \\
\hline $\begin{array}{l}\text { Fatty liver } \\
\text { Mild hepatitis } \\
\text { Severe hepatitis } \\
\text { Cirrhosis }\end{array}$ & $\begin{array}{r}22 \\
8 \\
6 \\
3\end{array}$ & $\begin{array}{l}0.47 \\
0.65 \\
0.44 \\
0.35\end{array}$ & $\begin{array}{l}0 \cdot 25-0 \cdot 68 \\
0 \cdot 36-0 \cdot 81 \\
0 \cdot 31-0 \cdot 81 \\
0 \cdot 25-4 \cdot 31\end{array}$ & $1 \cdot 09$ & NS & & $\begin{array}{l}\text { NS } \\
\text { NS } \\
\text { NS } \\
\text { NS }\end{array}$ \\
\hline $\begin{array}{l}\text { Inflammation grade: } \\
1 \\
2 \\
3\end{array}$ & $\begin{array}{r}24 \\
10 \\
5\end{array}$ & $\begin{array}{l}0.42 \\
0.7 \\
0.37\end{array}$ & $\begin{array}{l}0 \cdot 25-0 \cdot 65 \\
0 \cdot 52-2 \cdot 28 \\
0 \cdot 25-0.46\end{array}$ & $5 \cdot 88$ & 0.055 & $\begin{array}{l}2>1 \\
3<2\end{array}$ & $\begin{array}{l}0.081 \\
0.017\end{array}$ \\
\hline $\begin{array}{c}\text { Iron grade: } \\
1 \\
2\end{array}$ & $\begin{array}{r}30 \\
9\end{array}$ & $\begin{array}{l}0.53 \\
0 \cdot 37\end{array}$ & $\begin{array}{l}0.29-0.73 \\
0.15-0.74\end{array}$ & 0.97 & NS & & \\
\hline
\end{tabular}

^Units; $\mathrm{mm} / \mu \mathrm{mol}$ hepatic lipid/l, detector scale expansion 0.02 aufs.

TABLE III Hepatic total dienes (minimum $242 \mathrm{~nm}$ ) in relation to hepatic morphology

\begin{tabular}{|c|c|c|c|c|c|c|c|}
\hline \multirow[b]{2}{*}{ Histological group } & \multirow[b]{2}{*}{ No } & \multicolumn{2}{|c|}{ Total dienes $(\min 242 \mathrm{~nm})$} & \multirow[b]{2}{*}{ Anova $H$} & \multirow[b]{2}{*}{$p<$} & \multirow[b]{2}{*}{ Scheffe } & \multirow[b]{2}{*}{$p<$} \\
\hline & & Median * & IQ range & & & & \\
\hline $\begin{array}{l}\text { Fatty liver } \\
\text { Mild hepatitis } \\
\text { Severe hepatitis } \\
\text { Cirrhosis } \\
\text { Inflammation grade: }\end{array}$ & $\begin{array}{r}22 \\
8 \\
6 \\
3\end{array}$ & $\begin{array}{l}0.51 \\
1.06 \\
0.76 \\
0.79\end{array}$ & $\begin{array}{l}0.34-1.02 \\
0.53-1.85 \\
0.41-0.96 \\
0.78-2.87\end{array}$ & $4 \cdot 28$ & NS & $\begin{array}{l}2>1 \\
4>1\end{array}$ & $\begin{array}{l}\text { NS } \\
0 \cdot 074 \\
\text { NS } \\
0 \cdot 061\end{array}$ \\
\hline $\begin{array}{c}\text { Inflammation grade: } \\
1 \\
2 \\
3\end{array}$ & $\begin{array}{r}24 \\
10 \\
5\end{array}$ & $\begin{array}{l}0.51 \\
1.06 \\
0.68\end{array}$ & $\begin{array}{l}0.35-0.85 \\
0.58-1.85 \\
0.62-0.97\end{array}$ & $4 \cdot 18$ & NS & $\begin{array}{l}2>1 \\
3>1\end{array}$ & $\begin{array}{l}\text { NS } \\
0.041 \\
0.091\end{array}$ \\
\hline $\begin{array}{l}\text { Iron grade: } \\
1 \\
2\end{array}$ & $\begin{array}{r}29 \\
9\end{array}$ & $\begin{array}{l}0.67 \\
0.61\end{array}$ & $\begin{array}{l}0 \cdot 44-1 \cdot 26 \\
0 \cdot 38-1 \cdot 4\end{array}$ & $0 \cdot 12$ & NS & & \\
\hline
\end{tabular}

^Units; $\mathrm{mm} / \mu \mathrm{mol}$ hepatic lipid/, detector scale expansion $0 \cdot 02$ aufs.
After correction for lipid, the heights of the two diene absorption peaks were studied in relation to hepatic histology, inflammation grade, and iron grade (Tables II and III).

The diene signal at $233 \mathrm{~nm}\left(\mathrm{D}_{233}\right)$ showed no significant differences between groups when analysed by histological group (Table II; H 1.09, NS). When analysed according to inflammation grade, differences between groups just failed to

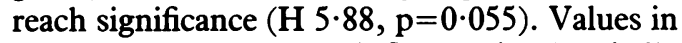
the group with moderate inflammation (grade 2 ), $\mathrm{n}=10$, median (interquartile range) $0.7(0.52-$ $2.28) \mathrm{mm} / \mu \mathrm{mol}$ tended to be greater than those in the severe (grade 3 ) and absent (grade 1) inflammation groups $(p<0.02$ and $p=0.081$ respectively). Total conjugated dienes were not related to iron grade (Table II).

The diene signal at $242 \mathrm{~nm}\left(\mathrm{D}_{242}\right)$ showed a similar pattern of results to those obtained for the $D_{233}$ signal (Table III). $D_{242}$ in hepatic biopsy specimens with cirrhotic changes and those with mild hepatitis tended to be greater than those with fatty liver $(p=0.074$ and $p<0.061$ respectively, NS). Compared with biopsy specimens without inflammatory changes (grade 1) those with inflammation (grades 2 or 3 ) tended to have higher $D_{242}$ values $(p<0.05$ and NS $p=0.091$ respectively).

The ratio $[9,11 \mathrm{LA}] \times 100 /[9,12 \mathrm{LA}](\mathrm{R})$ was measured in 21 biopsy samples (Fig 3). Numbers in each category are shown in the figure. When analysed by histological group (Fig 3(A)) significant differences emerged $(H=11 \cdot 44$, $\mathrm{p}<0.01)$. The two groups with hepatitis differed significantly from those with fatty liver (severe hepatitis, median (interquartile range) $4 \cdot 3(3 \cdot 37$ $5 \cdot 25), \mathrm{p}<0 \cdot 01$; mild hepatitis, $4 \cdot 35(3 \cdot 36-5 \cdot 38)$, $\mathrm{p}<0.005$; fatty liver, $2 \cdot 12(1 \cdot 73-2 \cdot 7))$. Similarly for inflammation grade (Fig 3(B)) a difference between the groups emerged overall $(H=8.95$, $\mathrm{p}<0.02$ ). Values were significantly greater in the two groups with a significant inflammatory component compared to those without (inflammation grade $3,4 \cdot 4(4 \cdot 3-6 \cdot 1), \mathrm{p}<0.005$; inflammation grade $2,3.4 \quad(2.94-4.8), \quad \mathrm{p}<0.05$; inflammation grade $1,2 \cdot 12(1 \cdot 78-3 \cdot 17))$. No significant differences were noted with regard to iron grade (Fig $3(\mathrm{C})$ ).

\section{HEPATIC GLUTATHIONE}

When analysed by histological grade, the hepatic glutathione content $(\mu \mathrm{mol} / \mathrm{g}$ protein) did not differ significantly between the groups (fatty liver, $35 \cdot 22(26 \cdot 1-44), n=23$; mild hepatitis, $30.92(23 \cdot 8-36 \cdot 9), \mathrm{n}=9$; severe hepatitis, $27 \cdot 25$ (11.9-41.0), $\mathrm{n}=6$; cirrhosis, $28 \cdot 82(19 \cdot 5-46 \cdot 1)$, $\mathrm{n}=3 ; \mathrm{H}=2 \cdot 15$, NS). For inflammation grade (Fig 4(A)) overall no intergroup differences emerged (inflammation grade $3,28.82$ (19.5$46 \cdot 1), n=5$; inflammation grade $2,30 \cdot 45(18 \cdot 6$ $33.5), \mathrm{n}=11$; inflammation grade $1,35.22$ (26.9-44.7), $\mathrm{n}=25 ; \mathrm{H}=3 \cdot 31$, NS), though the grouped data showed a significant trend to declining glutathione with increasing inflammation $(\mathrm{p}<0.05)$. Hepatic glutathione was significantly lower in the group with greater iron staining (grade 2, 21 $13(12 \cdot 9-30 \cdot 4), \mathrm{n}=9$; grade $1,33 \cdot 5(27 \cdot 9-45), \mathrm{n}=32 ; \mathrm{Z}=2 \cdot 95, \mathrm{p}<0.05$, Fig 4(B)). 


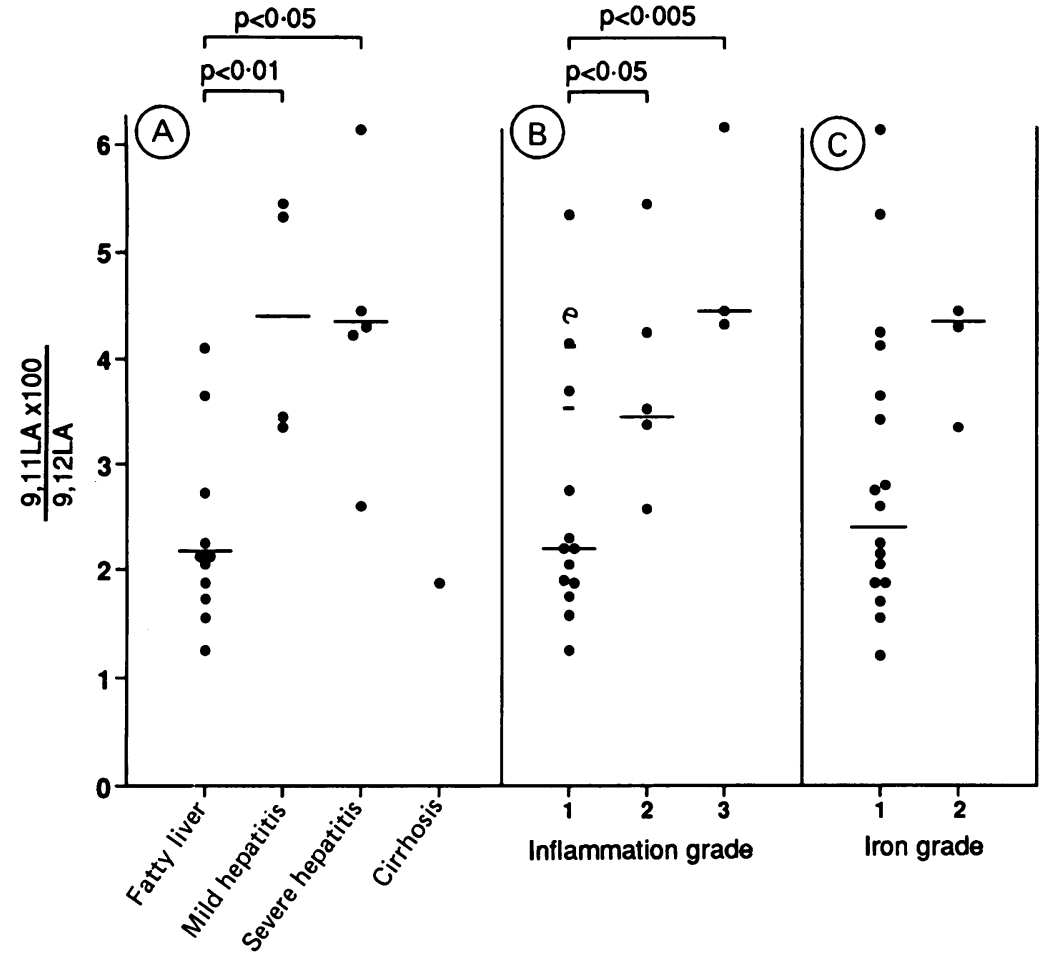

Figure 3: Conjugated dienes; $\star(9,11$ linoleic acid $(L A)) \times 100 /(9,12$ linoleic acid $(L A))(R)$ in hepatic biopsy specimens by histological grade and iron grade.

$\star_{M}$ Measired by reverse phase high performance liquid chromatography after hydrolysis of hepatic biopsy lipid extract (for conditions see text).

HEPATIC VITAMIN E ( $\mu$ MOL/MMOL)

When analysed by histological group, inflammation grade, and iron staining no significant differences emerged between the groups (Table IV). In 35 of 39 biopsy specimens concentrations of vitamin $\mathrm{E}$ fell below a value of $1.11 \mu \mathrm{mol} /$ mmol lipid $(0.8 \mathrm{mg} / \mathrm{g})$ regarded as indicative of vitamin $\mathrm{E}$ deficiency in serum ${ }^{23}$

CORRELATIONS

Multiple linear regression analysis after logarithmic transformation of data with either $D_{233}$, $\mathrm{D}_{242}$, or $\mathrm{D}_{233 / 242}$ as the dependent (y) variate and hepatic glutathione and vitamin $\mathrm{E}$ as independent variates showed no significant relations between hepatic antioxidants and total conjugated dienes. Hepatic glutathione correlated inversely with $\mathrm{R}(9,11 \mathrm{LA} \times 100 / 9,12 \mathrm{LA}) ; \mathbf{R}_{\mathrm{S}}=$ $-0.521 \mathrm{p}<0.02$.

\section{Discussion}

This is the first study to use derivative spectroscopy to identify conjugated dienes as indirect

TABLE IV Hepatic vitamin E:lipid ratio in relation to hepatic morphology

\begin{tabular}{|c|c|c|c|c|c|c|}
\hline \multirow[b]{2}{*}{ Histological group } & \multirow[b]{2}{*}{ No } & \multicolumn{2}{|c|}{ Vitamin E:lipid ratio } & \multirow[b]{2}{*}{ Anova $H$} & \multirow[b]{2}{*}{$p<$} & \multirow[b]{2}{*}{ Scheffe } \\
\hline & & Median ${ }^{\star}$ & IQ range & & & \\
\hline $\begin{array}{l}\text { Fatty liver } \\
\text { Mild hepatitis } \\
\text { Severe hepatitis } \\
\text { Cirrhosis } \\
\text { Inflammation grade: }\end{array}$ & $\begin{array}{r}22 \\
8 \\
6 \\
3\end{array}$ & $\begin{array}{l}0.45 \\
0.57 \\
0.37 \\
0.81\end{array}$ & $\begin{array}{l}0.28-0.96 \\
0.23-0.99 \\
0.28-0.63 \\
0.80-1.85\end{array}$ & $2 \cdot 82$ & NS & $\begin{array}{l}\text { NS } \\
\text { NS } \\
\text { NS } \\
\text { NS }\end{array}$ \\
\hline $\begin{array}{l}\text { Inniammation grade: } \\
1 \\
2 \\
3\end{array}$ & $\begin{array}{r}24 \\
10 \\
5\end{array}$ & $\begin{array}{l}0.46 \\
0.33 \\
0.6\end{array}$ & $\begin{array}{l}0.31-1.04 \\
0.23-0.87 \\
0.32-0.77\end{array}$ & 0.55 & NS & $\begin{array}{l}\text { NS } \\
\text { NS } \\
\text { NS }\end{array}$ \\
\hline $\begin{array}{l}\text { Iron grade: } \\
\quad \\
2\end{array}$ & $\begin{array}{r}30 \\
9\end{array}$ & $\begin{array}{l}0.46 \\
0.44\end{array}$ & $\begin{array}{l}0.28-1.03 \\
0.27-0.81\end{array}$ & 0.35 & NS & $\begin{array}{l}\text { NS } \\
\text { NS }\end{array}$ \\
\hline
\end{tabular}

«Units; $\mu$ mol vitamin $\mathrm{E} / \mathrm{mmol}$ lipid. markers of hepatic lipid peroxidation in alcoholic liver disease in man. Using this technique, we identified two minima at $233 \mathrm{~nm}$ and $242 \mathrm{~nm}$ in the second derivative spectrum of hepatic lipid extracts, which correspond to absorbance maxima in the conventional ultraviolet spectrum. Similar diene absorption spectra have been identified in hepatic microsomal lipid extracts from rats poisoned with carbon tetrachloride, which is known to generate hepatic lipid peroxidation. ${ }^{162}$ In those studies, the signal at $233 \mathrm{~nm}$ was found to increase in a linear fashion up to three hours after poisoning. ${ }^{26}$ Twenty four hours after ethanol poisoning in rats similar changes were also observed. ${ }^{26}$ These two minima have been attributed to mixtures of trans, trans and cis, trans hydroperoxydiene lipids and it is suggested that their relative proportions reflect the cellular redox status since the $233 \mathrm{~nm}$ signal appeared after the signal at $242 \mathrm{~nm} .{ }^{16}$ Furthermore, the appearance of the signal at $242 \mathrm{~nm}$ after carbontetrachloride poisoning could be prevented by pretreatment with the antioxidant vitamin E. ${ }^{16}$ In this study, a considerable variation was seen in the proportion of the two diene signals, with a suggestion that at higher levels of the $\mathrm{D}_{233}$ signal, the $\mathrm{D}_{242}$ signal diminished (Fig 1 ), though we could detect no evidence of a relation between these signals (or their ratio) and hepatic antioxidants. These findings suggest that for hepatic tissue the two minima represent absorption spectra of different species of conjugated diene lipids whose generation during lipid peroxidation in hepatic tissue does not conform to a strict stoichiometric pattern. The studies using alkaline hydrolysis and HPLC

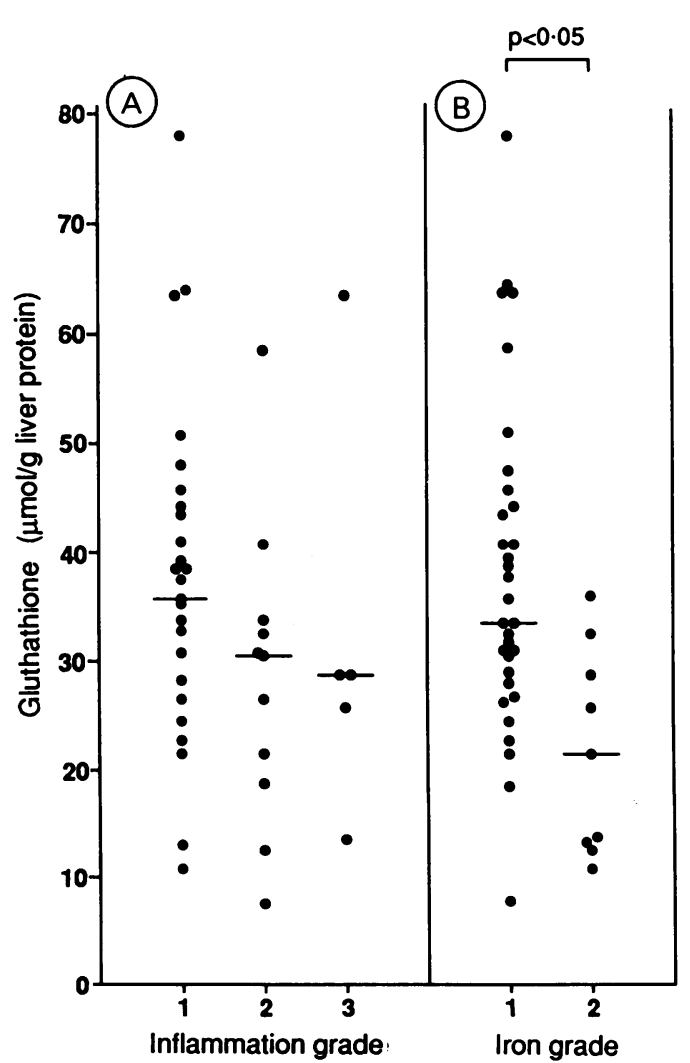

Figure 4: Glutathione ${ }^{\star}$ in hepatic biopsy specimens by inflammation grade and iron grade.

$\star$ For method see text. Results are expressed as $\mu \mathrm{mol} / \mathrm{g}$ liver protein. 
indicated that a proportion of diene conjugation within hepatic lipids exists as 9,11 LA, the fatty acid that accounts for $>90 \%$ of diene conjugation in serum, bile, and duodenal juice, ${ }^{131424}$ however, a number of other more polar ultraviolet absorbing peaks were detected at $234 \mathrm{~nm}$, which could be hydroperoxides. Their precise nature was not determined in the present study and the possibility that these peaks were generated in vitro during hydrolysis cannot be discounted. Future studies might therefore use phospholipase hydrolysis at $25^{\circ} \mathrm{C}$. ${ }^{27}$

We attempted to correlate changes in hepatic total dienes $\left(\mathrm{D}_{233}\right.$ and $\left.\mathrm{D}_{242}\right)$ with hepatic morphology. There was no clear relation with histological grade, though $\mathrm{D}_{233}$ and $\mathrm{D}_{242}$ signals tended to be greater in those biopsy specimens with moderate inflammation (Tables II and III).

For the 21 biopsy specimens for which measurements of the ratio $\mathrm{R} ;[9,11 \mathrm{LA}] \times 100 /$ $[9,12 \mathrm{LA}]$ were made a clearer picture emerged. Higher values for $\mathbf{R}$ were correlated with the presence of hepatitis and inflammation (Fig 3), although neither total dienes nor $\mathbf{R}$ correlated with the degree of iron deposition in the biopsy specimens (Tables II and III, Fig 3). Transition metals may play a catalytic role in free radical reactions, stimulating the decomposition of hydroperoxides to promote further lipid peroxidation, thus generating a wide variety of aldehydes including malonaldehyde which can react with thiobarbituric acid. ${ }^{28} 29$ Thiobarbituric acid reactive products have been previously detected in human hepatic biopsy material from alcoholics. ${ }^{12}$ In the present study a weak correlation between hepatic iron and inflammation grade was observed $\left(R_{S} 0 \cdot 355, n=41, p<0.02\right)$. The lack of a correlation between iron and $R$ or total dienes may indicate that iron deposition is a consequence of the ethanol induced hepatic injury rather than a cause.

Hepatic antioxidant status may play a critical role in the defence against oxidative stress. Glutathione functions with the enzyme glutathione peroxidase to reduce free lipid hydroperoxides and hydrogen peroxide. ${ }^{30}$ Furthermore, it is a cosubstrate for the peroxidation inhibiting protein which is capable of destroying hydroperoxide fatty acids located in phospholipids. ${ }^{31}$ Shaw et al detected increased hepatic diene conjugation and a reduction in glutathione in heavy drinkers, ${ }^{7}$ though other workers failed to confirm the findings for glutathione. ${ }^{32}$ In the present study, hepatic glutathione concentrations showed a trend to decrease with increasing inflammation grade (Fig 4) and increased iron grade was also associated with reduced hepatic glutathione $(p<0.05 ;$ Fig 4$)$, findings compatible with either diminished production or increased utilisation. Furthermore, there was a significant inverse correlation between $R$ and concentrations of the antioxidant glutathione $\left(R_{S}=-0.52, n=20, \quad p<0.02\right)$. Additional information in respect of hepatic redox state might have been provided by utilising an enzymic method of glutathione determination which may also be used to determine oxidised gluthathione ${ }^{33}$ and in view of the present findings this may be considered in future studies.

Since vitamin $\mathrm{E}$ represents the major source of chain breaking antioxidant activity in membranes $^{34}$ and our previous studies have indicated impaired vitamin $\mathrm{E}$ status in alcoholics, ${ }^{23}$ we assessed hepatic vitamin $\mathrm{E}$ status. Concentrations varied considerably between biopsy specimens (median $0.46 \mu \mathrm{mol} / \mathrm{mmol}$, range 0.04 $2 \cdot 56$, Table I), and in 35 of the 39 biopsy specimens fell below $1 \cdot 11 \mu \mathrm{mol} / \mathrm{mmol}(0.8 \mathrm{mg} /$ g), a value which has been quoted as the threshold for vitamin E deficiency in serum ${ }^{23}$ and is associated with increased peroxide fragility of red cells. However, the applicability of such figures to hepatic lipids is unknown. We could detect no significant differences in respect of hepatic vitamin $\mathrm{E}$ and any of the morphological characteristics we assessed (Table IV).

The hypothesis that ethanol can induce hepatic injury through a mechanism involving free radical induced lipid peroxidation is not new.' Debate continues over a possible mechanism for free radical generation in response to ethanol. Slater ${ }^{2}$ has proposed that ethanol is converted to a hepatotoxic ethoxy radical $\left(\mathrm{C}_{2} \mathrm{H}_{5}\right.$ 0.), whilst Reitz ${ }^{3}$ implicated the microsomal enzyme system. When ethanol ingestion is high it has been suggested that an alternative pathway for the metabolism of acetaldehyde involving mixed function cytochrome $\mathbf{P}_{450}$ oxidase activity may generate free radicals. ${ }^{4}$ Lewis and Paton proposed that the superoxide radical could be generated within areas of relative hypoxia in the liver from acetaldehyde via xanthine oxidase. ${ }^{5}$ Alternatively, lipid peroxidation might result from the effects of reactive oxygen species liberated by infiltrating inflammatory cells ${ }^{17}$ as a result of hepatitis. Our data suggest that heavy alcohol consumption leads to hepatic inflammation and lipid peroxidation. Though the precise mechanism for its generation could not be determined, the correlation with inflammatory histological features and the relation with hepatic glutathione raise the possibility that the process of ethanol induced hepatic injury may be modulated either by agents to stimulate hepatic glutathione regeneration or by strategies involving antioxidants. A trial of this treatment in alcoholic hepatitis would be one possibility.

1 di Luzio NR, Hartman AD. Role of lipid peroxidation in the pathogenesis of the ethanol-induced fatty liver. Fed Proc Am Soc Exp Biol 1967; 26: 1436-42.

2 Slater TF. In: Lagnado JR, ed. Free radical mechanisms in tissue injury. London: Pion Ltd, 1972: 4-239.

3 Reitz RC. A possible mechanism for the peroxidation of lipids due to chronic ethanol ingestion. Biochim Biophys Acta 1975; 380: 145-54.

4 Thurman RG, Ley HC, Scholz R. Hepatic microsomal ethano oxidation. Hydrogen peroxide and the role of catalase. Eur 7 oxidation. Hydrogen perox
Biochem $1972 ; 25: 420-30$.

5 Lewis K, Paton A. Could superoxide cause cirrhosis? Lancet 1982; ii: 188-9.

6 Dianzani MM. The role of free radicals in liver damage. Pro Nutr Soc 1987; 46: 43-52.

7 Shaw S, Rubin KP, Lieber CS. Depressed hepatic glutathione and increased diene conjugation in alcoholic liver disease. Dig Dis Sci 1983; 28: 585-7.

8 Lauterberg BH, Davies S, Mitchell JR. Ethanol suppresses hepatic glutathione synthesis in rats in vivo. $\mathcal{J}$ Pharmacol Exp Ther 1984; 1:7-11.

9 Di Luzio NR. Protective effect of vitamin E on plasma lipid dienes in man. 7 Agric Food Chem 1972; 20: 487-90.

10 McDonald CM. The effects of ethanol on hepatic lipid peroxidation and on the activities of glutathione reductase peroxidation and on the activities of glutathione
and peroxidase. FEBS Lett 1973; 35: 227-30.

11 Shaw S, Jayatilleke R, Ross WA, Gordon ER, Leiber CS Ethanol induced lipid peroxidation; potentiation by chronic Ethanol induced lipid peroxidation; potentiation by chronic
alcohol feeding and attenuation by methionine. $\mathcal{F}$ L ab Clin Med 1981; 98: 417-25. 
12 Suematsu T, Matsumura T, Sato N. Lipid peroxidation in alcoholic liver disease in humans. Alcoholism: Clin Exp Res 1981; 5: 427-30.

13 Cawood P, Wickens DC, Iversen SA, Braganza JM Dormandy TL. The nature of diene conjugation in human serum, bile and duodenal juice. FEBS Lett 1984; 171: 320 24

14 Fink R, Clemens MR, Marjot DH, et al. Increased free radical activity in alcoholics. Lancet 1985; ii: $291-4$.

15 Corongui FP, Milia A. An improved and simple method fo determining diene conjugation in autoxidised polyunsaturated fatty acids. Chem Biol Interact 1983; 44: 289-97.

16 Corongui FP, Poli G, Dianzani MU, Cheesman KH, Slater TF. Lipid peroxidation and molecular damage to polyunsaturated fatty acids in rat liver. Recognition of two classes of hydroperoxides formed under conditions in vivo. Chem Biol Interact 1986; 59: 147-55.

17 Babior BM. Oxygen dependent microbial killing of Babior BM. Oxygen dependent microbia

phagocytes. $N$ Englf Med 1978; $298: 721-5$.
18 Wills ED. Lipid peroxide formation of microsomes. The role of non haem iron. Biochem 7 1969; 113: 325-32.

19 Gutteridge JMC, Richmond R, Halliwell B. Inhibition of the iron catalysed formation of hydroxyl radicals and of lipid peroxidation by desferioxamine. Biochem $\mathcal{F} 1979 ; 184: 469$ 72.

20 Wills ED. Mechanisms of lipid peroxide formation in tissues. Role of metals and haematin proteins in the catalysis of the (acids. Brochim Biophys Acta 1965; 98: 238-51.

21 Burton GW, Webb A, Ingold KU. A mild rapid and efficien method of lipid extraction for use in determining vitamin $\mathrm{E} /$ method of lipid extraction for use in

22 Snyder T, Stephens N. A simplified spectrophotometric method for determination of ester groups in lipids. Biochim Biophys Acta 1959; 34: 244-5.

23 Thurnham DI, Davies JA, Crump BJ, Situnayake RD, Davi $M$. The use of different lipids to express serum tocopherol: lipid ratios for the measurement of vitamin E status. $A n n$ Clin Biochem 1986; 23: 514-20.
24 Iversen SA, Cawood P, Dormandy TL. A method for the measurement of a diene conjugated derivative of linoleic acid measurement of a diene conjugated derivative of linoleic acid 18:2 $(9,11)$ in serum phospholipid
Ann Clin Biochem 1985; 22: 137-40.

25 Beutler E, Duron O, Kelly B. An improved method for the determination of blood glutathione. F Lab Clin Med 1963; 61: $822-6$

26 Corongui FP, Lai H, Milia A. Carbontetrachloride, bromotrichloromethane and ethanol acute intoxication. New chemical evidence for lipid peroxidation in rat tissue microsomes. Biochem $\mathcal{F}$ 1983; 212: 625-31.

27 Griffen JFA, Wickens DG, Tay SK, Singer A, Dormandy TL. Recognition of cervical neoplasia by the estimation of a free radical reaction product (octadeca-9,11 dienoic acid) in biopsy material. Clin Chim Acta 1987; 163: 143-8.

28 Gutteridge JMC, Stocks J, Dormandy TL. Thiobarbituric acid reactive substances derived from autoxidising linoleic acid reactive substances derived from autoxidising 1 .

29 Esterbauer H. In: McBrien DC, Slater TF, eds. Free radicals, lipid peroxidation and cancer. London: Academic Press, lipid peroxida

30 McCay PB, Gibson DD, Hornbrook KR. Glutathione dependent inhibition of lipid peroxidation by a soluble heat labile factor, not glutathione peroxidase. Fed Proc 1981; 40: 199-205.

31 Ursini F, Maiorino H, Valente M, Ferri L, Gregolin C. Purification from guinea pig liver of a protein which protects liposomes and biomembranes from peroxidative degradation and exhibits glutathione peroxidase activity in phosphatidyl choline hydroperoxides. Biochim Biophys Acta 1982; 710: 197-211.

32 Poulson HE, Ronek L, Andreasen PB. The hepatic glutathione content in liver diseases. Scand $\mathcal{f}$ Clin Lab Invest thione content

33 Tietze F. Enzymic method for quantitative determination of nanogram amounts of total and oxidised glutathione. Anal Biochem 1969; 27: 502-22.

34 Diplock AT. In: Biology of Vitamin E. Ciba Found Symp 1983; 101: 45-53. 